\title{
O discurso do cidadão de bem e a lógica do supereu
}

\section{The good citizen's speech and the logic of the superego}

\author{
Artur Julio de Albuquerque Junior (orcid.org/0000-0001-5992-2251)1 \\ João Luiz Leitão Paravidini (orcid.org/0000-0002-2685-3808)²
}

\begin{abstract}
Resumo
O objetivo deste trabalho é propor uma reflexão acerca dos fundamentos subjetivos daquilo que alegoricamente denominamos de discurso do cidadão de bem. Postulamos que a articulação da dimensão discursiva do cidadão de bem é homóloga à paradoxal dialética da ação do supereu, que circunscreve o regime da lei, ao mesmo tempo em que resguarda, em sua constituição mais elementar, um estatuto completamente fora da lei. Analisamos, por fim, os efeitos dessa conjuntura a partir de algumas reações sociais frente a um acontecimento proveniente do campo da arte: a exposição "Queermuseu”. Ressaltamos que as reivindicações dos cidadãos de bem que proclamam a defesa da família, da moral e dos bons costumes denunciam o ímpeto, desses sujeitos, em sobrepujar as condições de seus próprios ideais.
\end{abstract}

Palavras-chave: Psicanálise. Cidadão de bem. Supereu. Arte.

\begin{abstract}
The objective of this work is to propose a reflection about the subjective foundations of what we allegorically call of good citizen's speech. We postulate that the articulation of the discursive dimension of the good citizen is homologous to the paradoxical dialectics of the action of the superego, which circumscribes the regime of the law, while at the same time safeguards, in its most basic constitution, a statute completely outside the law. Finally, we analyze the effects of this conjuncture from some social reactions to an event coming from the field of art: the exhibition "Queermuseu". We emphasize that the claims of the good citizens, who proclaim the protection of family, moral and decency, denounce the impetus, of these subjects, to overcome the conditions of their own ideals.
\end{abstract}

Keywords: Psychoanalysis. Good citizen. Superego. Art.

\footnotetext{
1 Universidade Federal de Uberlândia, Uberlândia, Brasil. E-mail: artur26junior@gmail.com.

2 Universidade Federal de Uberlândia, Uberlândia, Brasil. E-mail: jlparavidini@gmail.com.
} 
O que teve início com o pai se completa na massa.

(Freud, 1930[2010a], p. 105)

Desde Freud nós sabemos que a Psicanálise não se configura como um saber que introduz barreiras intransponíveis entre o campo do social e o do individual. Apesar de muitas críticas dirigidas à Psicanálise alegarem que o viés analítico apenas se preocupa com as questões singulares, desconsiderando as implicações dos contextos sociais, encontramos em Freud textos amplamente voltados para a análise da dimensão social. Por exemplo, em "Psicologia das Massas e Análise do Eu", nos deparamos com o seguinte: "Na vida psíquica do ser individual, o Outro é via de regra considerado enquanto modelo, objeto, auxiliador e adversário, e portanto a Psicologia individual é também, desde o início, Psicologia Social, num sentido ampliado, mas inteiramente justificado" (Freud, 1921 [2011], p. 14).

Em outro texto freudiano, de marcante prevalência da dimensão social, "Totem e Tabu" (1913[1996a], p. 85), Freud propõe uma fascinante comparação entre o tabu e a neurose obsessiva, alegando a relevância dessa articulação pelo fato de que ela pode "fazernos compreender a natureza da relação entre as diferentes formas de neuroses e instituições culturais e perceber como o estudo da Psicologia das neuroses é importante para a compreensão do desenvolvimento da civilização". Em outras palavras, Freud sublinha que o estudo das neuroses, mesmo em seu aspecto de âmbito singular, pode nos ajudar a pensar elementos que se instituem no campo da cultura a partir dos laços sociais. O ponto que fundamenta tal proposição é o da relação que Freud afirma existir entre as neuroses e as instituições culturais.

As neuroses, por um lado, apresentam pontos de concordância notáveis e de longo alcance com as grandes instituições sociais, a arte, a religião e a filosofia. Mas por outro lado, aparecem como se fossem distorções delas. Poder-se-ia sustentar que um caso de histeria é a caricatura de uma obra de arte, que uma neurose obsessiva é a caricatura de uma religião e que um delírio paranoico é a caricatura de um sistema filosófico. (Freud, 1913[1996a], p. 85). 
"Poder-se-ia sustentar que uma neurose obsessiva é a caricatura de uma religião", isto é, uma neurose obsessiva pode ser concebida como uma distorção de algo que se institui no campo do social. Em outro texto de viés social, "O mal-estar na civilização" (1930[1996b], p. 52), Freud pontua que "a religião seria a neurose obsessiva universal da humanidade". Aqui, novamente é operada uma torção entre neurose obsessiva e instituição cultural. O que mais nos interessa nessas afirmações é a articulação que Freud tensiona entre o plano do social e o do patológico. Sem imiscuir um no outro, a construção de Freud aproxima esses dois registros - do social e do singular - guardando suas respectivas particularidades para poder pensar o que um pode nos ensinar a respeito do outro.

Essa é uma operação de simultaneidade entre aproximação e distanciamento, por isso não se trata de propor uma eventual patologização da cultura, assim como não vemos que é isso que está sendo executado quando Freud problematiza a relação das neuroses com as instituições sociais. O campo de investigação psicanalítico possibilita compor elementos que nos permitem operar tanto a dimensão social quando a singular, sem querer fazer uma desaparecer em conluio com a outra. Uma boa maneira de articular essas duas dimensões é pela via do conceito de sintoma.

Para Lacan (1966[1998a]), a noção de sintoma, no sentido apreendido pela Psicanálise, já havia surgido antes mesmo de Freud. A origem dessa articulação conceitual residiria na crítica feita por Marx ao produzir uma reviravolta a partir de Hegel. Essa retomada marxista é compreendida por Lacan como um retorno da questão da verdade. Esse acontecimento traz enfoque para "uma dimensão que poderíamos dizer do sintoma, que se articula por apresentar o retorno da verdade como tal na falha de um saber" (Lacan, 1966[1998a], p. 234). A leitura que Lacan faz de Marx, colocando-o como inventor do sintoma no sentido freudiano, propõe uma articulação entre sintoma e a dimensão da verdade.

A verdade, aqui posta em questão, não funciona na lógica do signo, mas sim na articulação entre os significantes, isso quer dizer que o sintoma não pode ser considerado como aquilo que representa uma irrupção da verdade, o sintoma é verdade. Sintoma e 
verdade são materialisticamente oriundos da mesma fonte, talhados da mesma madeira, ambos se instauram a partir da cadeia significante (Lacan, 1966[1998a]).

A convocação, feita por Lacan do texto marxista, para pensar as origens do conceito de sintoma, institui uma problemática sobre a distinção entre sintoma social e sintoma individual. Podemos conceber uma definição do sintoma neurótico a partir da função particularizante que este exerce para um sujeito, ou seja, o sintoma individual se constrói a partir da maneira como cada sujeito goza de sua dimensão inconsciente. Já o sintoma social é o que traz a marca que caracteriza uma sociedade inscrita sob a rubrica de uma determinada época. Assim, em sua dimensão social, o sintoma é a verdade que sustenta uma lógica estabelecida de aparelhamento coletivo do gozo (Vanier, 2002). Propomos aqui pensar que uma das lógicas discursivas que se enunciam como verdade de um gozo coletivo na contemporaneidade é aquela fundamentada na alegoria do cidadão de bem.

Um dos chavões que se destacam na atual escatologia da vida cotidiana é o messianismo sacramentado na referência ao cidadão de bem. Honroso e quase sempre indignado, o cidadão de bem vem assumindo um posto de destaque em narrativas radicais que reivindicam a defesa da família, da moral e dos bons costumes. O termo "defesa" é interessante nessa conjuntura, o que nos leva a pensar: qual é o ataque? O que é tão ameaçador para o cidadão de bem que resulta em um recrudescimento subjetivo, levando à produção de posturas radicais que tentam bruscamente repelir o diferente, o sexual e o subversivo?

Para responder a essa pergunta, precisamos retomar aquilo que caracteriza os laços sociais na vida contemporânea. A falta de referenciais sólidos que ordenam nossa relação social com os valores morais, com os costumes considerados "bons" e com a organização familiar que atende à tradição parece ter gerado um clima de insegurança generalizada em alguns sujeitos com maior necessidade de se ater às normas e padrões previamente canonizados. A metáfora de Bauman (2001) nos esclarece que um dos efeitos da liquidificação de nossas organizações sociais produz uma sensação de instabilidade que facilmente se transforma em medo.

A modernidade Líquida arrefeceu os baluartes sociais que asseguravam 0 norteamento dos sujeitos. A igreja, o Estado, o exército, o chefe de família ou qualquer 
outra instituição social que pudesse assumir esse lugar de ordenador de uma lei perderam força na transição para a pós-modernidade. A libertação das sólidas amarras institucionais se deu de modo proporcional à instalação de um sentimento de medo e insegurança social. Quanto mais líquida se torna uma organização social, mais intensos são os sentimentos de insegurança que sobrevêm nos sujeitos que vivem nessas circunstâncias (Bauman, 2001).

Podemos entender o fenômeno da liquidez social, em termos psicanalíticos, como uma desconsistencialização do Outro, ou seja, o esfacelamento das balizas simbólicas que regem os laços socais. O que temos na contemporaneidade é um Outro com buracos escancarados, ou seja, incompleto e sem garantias. Cabe destacar que o Outro lacaniano é por definição incompleto por um princípio estrutural. A linguagem, matéria-prima que o constitui, ressalta seu estatuto inexoravelmente contingencial. No entanto, na modernidade, o Outro era mais facilmente revestido com semblantes de completude, sua consistência ou solidez o tornava crível e respeitável. As normas que se impunham a partir de seu referencial eram seguidas com mais resignação e obediência.

O Outro contemporâneo é um Outro destituído de seus semblantes e baluartes tradicionais que Ihe davam um aspecto de consistência. A modernidade líquida, fenômeno histórico-contingencial, põe em evidência um traço estrutural do Outro, a saber, o Outro enquanto barrado, ou ainda como também se pode ler tal formulação, o Outro como inexistente. E isso não é sem consequências, um dos efeitos mais significativos dessa reviravolta social é o surgimento de uma operação de salvamento do Outro em sua pretensa consistência (Lustoza, Cardoso \& Calazans, 2014). Não seria o salvamento do Outro em seu semblante de completude que traduziria o coro dos cidadãos de bem de que é preciso salvar a família, a moral e os bons costumes?

O objetivo deste trabalho é propor uma reflexão acerca dos fundamentos subjetivos daquilo que alegoricamente denominamos de discurso do cidadão de bem. Para isso, propomos uma articulação entre essa dimensão discursiva do cidadão de bem e a lógica paradoxal do que Freud (1923[1996d]) nomeia de supereu, agente psíquico que circunscreve o regime da lei, ao mesmo tempo que resguarda, em sua constituição mais elementar, um estatuto completamente fora da lei. Tal conjuntura posteriormente será 
analisada a partir de reações sociais frente a um acontecimento proveniente do campo da arte: a exposição "Queermuseu". Ressaltaremos, por fim, que as reivindicações dos cidadãos de bem que proclamam a defesa da família, da moral e dos bons costumes denunciam o ímpeto, desses sujeitos, em sobrepujar as condições de seus próprios ideais.

\section{O cidadão de bem e a lógica do supereu}

A alegoria ${ }^{3}$ que propomos acerca da figura discursiva do cidadão de bem, posição combativa que reivindica a defesa da moral, da família e dos bons costumes, enuncia em suas violentas relutâncias uma relação justamente com o oposto de seus pretensos ideais. $\mathrm{O}$ imperioso ímpeto de rechaçar aquilo que é da ordem da sexualidade aponta inversamente para a própria dimensão do sexual que parece forcejar para se fazer valer, ainda que seja por meios violentos.

A lei do cidadão de bem, portanto, é uma lei insensata. Isso porque no ato de elidir violentamente os impasses da sexualidade é que essa figura enuncia que é precisamente do sexual que provém seus impulsos mais fundamentais. Trata-se de um contradito estrutural que alia a dimensão da lei com os estímulos que visam sobrepujar a própria lei. Assim, a lógica desse funcionamento discursivo nos remete ao que Freud (1914[1996c]) inicialmente denominou de um "agente psíquico especial", ganhando posteriormente em seu texto "O eu e o isso" (1923[1996d]) o nome definitivo de supereu. Tracemos então algumas marcações desse operador psíquico.

Nos "Três ensaios sobre a teoria da sexualidade", Freud (1905[1996e]) salienta que, no início da vida humana, as pulsões se satisfazem de um modo autoerótico, ou seja, extraindo prazer do próprio corpo. Nesse momento, denominado de narcisismo primário, os objetos de investimento da libido são partes do próprio corpo do pequeno ser humano que ainda não instituiu a dimensão de um Eu (Je). O narcisismo primário se caracteriza como um momento de indiferenciação imaginária com o outro, no qual o bebê vivencia uma sensação

\footnotetext{
3 O conceito de alegoria que utilizamos nesse contexto fundamenta-se nas formulações de Walter Benjamin, para o qual alegoria é o um elemento de representação que possibilita "expressar uma outra construção de visão de mundo e a potência de revelar as iniquidades que se encontram detrás dessa falsa totalidade harmoniosa, pautada, sobretudo, nas fantasmagorias das relações sociais e econômicas entre os seres humanos" (Freitas, 2014, p. 12).
} 
de onipotência. A "majestade, o bebê" se configura como um estado de perfeição narcísica que institui o Eu ideal (Freud, 1914[1996c]).

Podemos pensar nesse Eu ideal como um Eu que ainda não foi seccionado pelo corte da linguagem. Estamos falando de um ser que ainda não sofreu as incidências do cenário edípico, em que a lei paterna marca uma limitação ao gozo e inaugura uma experiência de castração. Trata-se, portanto, de uma relação simbiótica que a criança mantém com o outro materno. A alienação dessa relação vai ser fraturada caso a cena edípica introduza um novo elemento entre a criança e o outro materno: o Nome-do-Pai. O significante Nome-do-Pai é aquele que, em função de interveniência, instaura para a criança a proibição do incesto, ou a impossibilidade de manter-se naquela relação de perfeição narcísica com o outro materno. O Nome-do-Pai é o significante que introduz a dimensão simbólica da castração (Nasio, 1997).

Diante da experiência da castração e da consequente perturbação do narcisismo primário, a criança é confrontada com seus anseios de retornar àquela relação homeostática com o outro, mas, para isso, agora será preciso que ela conquiste o amor desse outro. Vias mais árduas se insinuam. Aqui, posteriormente à diferenciação com o outro, já podemos falar da existência de um Eu (Je). Lacan se dedica a pensar nessa passagem com sua teoria do estádio do espelho, momento em que a alienação com a imagem do outro vai gradativamente se separando, para, a partir do referencial externo do outro, formar uma imagem na qual a criança vai se identificar. O resultado dessa operação é o narcisismo em sua segunda configuração, o narcisismo secundário (Nasio, 1997).

O segundo momento do narcisismo implica no fato de que, para investir a libido no próprio Eu, agora é preciso fazê-lo primeiramente em direção aos objetos externos para depois efetuar o retorno do investimento libidinal para o si mesmo, "Enquanto, com o narcisismo primário, o outro era o si mesmo, a partir daí só é possível experimentar-se através do outro" (Nasio, 1997, p. 56). A partir do narcisismo secundário, da separação entre o eu e o outro, da incidência da castração veiculada pelo significante paterno no cenário edípico, a sensação de plenitude narcísica vivida no narcisismo primário se esvai. Agora o Eu vai precisar buscar o amor do outro, esforçando-se para ser aquilo que julga 
que precisa ser para ser reconhecido, isto é, amado. Mas como o Eu irá aferir o que precisa tornar-se para ser amado? Qual é o modelo que dita o protótipo a ser seguido? Essa função será exercida pelo ideal do Eu.

Por não conseguir manter a perfeição de completude do narcisismo primário (Eu ideal), o Eu vai tentar reavê-lo sob a forma de um modelo, um conjunto de ideais que vai regular sua dimensão narcísica (Ideal de Eu). O ideal do Eu então vem "de fora", e vai ser transmitido primeiramente pela influência parental e posteriormente pelas interferências mais amplas do meio social e cultural. No texto sobre o narcisismo, Freud (1914[1996c]) demarca que existe, portanto, um "agente psíquico especial" que tem a função de fomentar exigências sobre o Eu para que ele atenda ao modelo estabelecido pelo ideal do Eu. "Esse ‘agente psíquico especial' atua em forma de consciência, auto-observação e vigia, manifestando-se sempre por uma voz" (Campos, 2015, p. 65).

Já em "O eu e o isso", com a formulação da segunda tópica, Freud (1923[1996d]) apresenta a nomenclatura definitiva desse agente psíquico especial, que passa a ser chamado de supereu. O supereu é, portanto, um agente psíquico que tem a função de fazer exigências ao Eu, sendo que seu parâmetro é o conjunto de ideais que constituem o Ideal de Eu. Essa vertente do supereu é a da consciência moral, é a face que requer o seguimento da lei que foi introjetada a partir das identificações parentais. Esse é o viés do supereu como herdeiro do complexo de Édipo. Aqui podemos situar o imperativo categórico de Kant, ou seja, o dever incondicional de fazer valer os cânones da lei moral.

No entanto, é preciso que nos atentemos para a duplicidade inerente à constituição do supereu. Se por um lado o supereu, em sua faceta de assegurador da lei moral, é herdeiro do complexo de Édipo, esse agente psíquico especial também é herdeiro do Isso. Assim, originário também das escolhas objetais do Isso, o supereu tem uma composição mais arcaica, vinculada às pulsões que se articulam ao Isso, formando desse modo uma outra variante de imperativo: o do gozo. Isto é, "as escolhas objetais do Isso expressam um supereu arcaico [imperativo do gozo], ao passo que a formação reativa contra essas escolhas expressa um supereu desenvolvido, resultado do declínio do complexo de Édipo [imperativo categórico]" (Campos, 2015, p. 70). 
A incidência do supereu promove uma divisão no mundo simbólico do sujeito em dois: por um lado, vigora a parte que exige o cumprimento da lei moral, e outra parte, mais arcaica, que rejeita a imposição da lei, ou seja, um segmento fora da lei. Eis aí o disparate do supereu. No núcleo da composição de sua lei, reside o grão de insensatez que diz da incompreensão da lei. Por isso, "o sujeito nunca consegue apreender a lei no seu conjunto, e a lei nunca é assumida completamente. Pode-se deduzir disso que a lei é não-toda" (Campos, 2015, p. 168). No entanto, mesmo que a lei não seja compreendida pelo sujeito, ela é exercida por ele. Na medula do supereu, arauto da lei, viceja algo que escapa à apreensão do sentido, e é justamente no fora de sentido que reside o fundamento do supereu e da censura. Em outras palavras, o que se depreende disso é que "há algo da lei que pertence ao fora da lei" (Campos, 2015, p. 168).

Para entendermos a paradoxal composição do supereu, faz-se necessário marcar que a lei não é apenas algo simbólico que regula os laços sociais entre as pessoas. No núcleo da lei, encontramos seu estatuto de real, alheio às articulações de sentido. É nesse caroço da lei, pertencente ao campo do real, que podemos circunscrever a raiz do supereu. Portanto, ao formularmos a lógica paradoxal do supereu em sua dimensão mais arcaica, mais primordial e elementar, delineia-se, assim, "uma lei para além de toda lei" (Lacan, 1959-1960[2008], p. 31). Que lei poderia ser essa, senão a implacável lei da pulsão de morte?

Com o "Além do princípio do prazer", Freud (1920[2010b]) apresenta a segunda teoria das oposições pulsionais. Ao abandonar a antiga concepção que trazia a tensão entre as pulsões do eu (ou pulsões de conservação) e as pulsões sexuais, ele passa a reconfigurar a dinâmica psíquica entre as pulsões de vida (pulsões sexuais e pulsões do eu) e as pulsões de morte. A teoria metapsicológica a respeito da pulsão de morte é a tentativa de Freud de formalizar uma certa tendência inerente a todos os seres vivos de se dirigirem para o inanimado, para o silenciamento de todo e qualquer estímulo que possa perturbar a homeostase psíquica. Esse estado só pode ser atingido mediante o desvanecimento do próprio organismo, ou seja, com sua morte. 
Para Freud (1920[2010b]), o princípio do prazer está na verdade a serviço das pulsões de morte. Se o princípio do prazer regula a dinâmica do aparelho psíquico de modo a tentar manter a quantidade de excitação nele tão baixa quanto possível, é apenas na morte do psiquismo que esse objetivo poderia ser plenamente alcançado. Essa afirmação permite-lhe estabelecer a pulsão de morte como a pulsão por excelência. Posteriormente, Lacan (1960-1964[1998b, p. 863] irá retomar esse ponto da formulação freudiana sobre as pulsões para sustentar que, de fato, "toda pulsão é virtualmente pulsão de morte".

Voltando ao supereu, podemos estabelecer uma relação intrínseca entre o imperativo do gozo e a força motriz da pulsão de morte, já que o gozo, como afirma Lacan (19691970[2007], p. 17), "é o caminho para a morte". Freud (1920[2010b]) ainda propõe que a agressividade humana é uma resultante da pulsão de morte que perpassa os homens e suas formações sociais. Essa proposta posteriormente vai ser mais explorada com a produção do texto "O mal-estar na civilização" (Freud, 1930[1996b]). Assim, é possível entendermos que o gozo é um dos nomes lacananianos para a pulsão de morte postulada por Freud. A agressividade e a violência surgem como expressões dessa "força demoníaca" (Freud, 1920[2010b]) que nos impele para a destruição do outro e de nós mesmos. A agressividade e a violência, portanto, são a essência do supereu.

No supereu, reina uma pura cultura de morte. Suas exigências atrozes ao Eu o caracterizam como uma figura feroz que de modo sádico faz com que o Eu se torne masoquista, despendendo grandes investimentos de agressividade para sua própria destruição. A voz do supereu sempre se faz ouvir pelas intempéries de suas reivindicações extremadas, cuja principal formulação pode ser resumida na seguinte sentença: Goze! O comando é imperioso e forceja por vociferar contra o Eu, resultando em inibições, sintomas e angústias.

Até aqui temos privilegiado o aspecto subjetivo do supereu, ou seja, sua inscrição como instância reguladora que compõe a dimensão tópica do aparelho psíquico. Entretanto, nos atentemos agora para o supereu em sua constituição social. Esse giro é fundamental para fazermos a articulação entre os modos de funcionamento do supereu e a figura alegórica do cidadão de bem que vemos cotidianamente proliferar na contemporaneidade. Para além, então, do supereu "individual", Freud (1930[1996b]) menciona um supereu 
cultural. Sua constituição, no âmbito social, seria marcada pelos líderes que influenciaram as características éticas de uma determinada cultura ao longo de sua história.

O supereu cultural elaborou seus ideais, assim como estabeleceu suas exigências, de sorte que procurou situar, através de uma censura, as relações entre os humanos. Esse controle de qualidade das relações entre os homens, designado de ética, visa uma tentativa terapêutica das relações entre os homens e entre o homem e a sociedade. O supereu cultural, com severidade, estabelece ideais éticos para serem obedecidos, sem se preocupar com a capacidade que cada sujeito tem, para atender as suas exigências. (Campos, 2015 , p. 101).

A incidência do supereu cultural, inclusive, é o que podemos situar, a partir do "O mal-estar na civilização" (Freud, 1930[1996b]), como um dos principais aspectos apontados por Freud para compreender a origem do mal-estar inerente aos enlaces sociais. As exigências de severas restrições em nome de determinados ideais morais em constante tensão com os anseios do desejo é o ponto norteador desse trabalho freudiano sobre a civilização. Não podemos, contudo, nos esquecer de que o supereu não é apenas uma chancela de restrições. Sua outra face é, na verdade, o vigoroso mandamento de levar ao termo os mais mortíferos intentos do gozo. Cabe-nos perguntar aqui: quais seriam os efeitos na constituição do supereu contemporâneo, decorrentes da desconsistencialização do Outro? Poderíamos conjecturar que a liquidificação do Outro resultaria no enrijecimento do supereu social?

Se levarmos em consideração que o supereu, pelo menos em sua perspectiva herdeira do complexo de Édipo, advém da identificação do comando parental, em uma época na qual o pai não se faz mais tão sólido como o era na modernidade, poderíamos suspeitar que o supereu possa extremar-se numa tentativa de fazer suplência imaginária ao pai simbólico que antes detinha a função do ordenamento social. Desse modo, o discurso do cidadão de bem, e a violência que ele veicula a favor de ideais de normatização balizadas por preceitos morais, parece ser uma forma de expressão de um supereu cultural que, 
impedido de atingir seus intentos sexuais, se esforça violentamente para censurar o sexual no Outro. "O ato violento produz um gozo" (Campos, 2015, p. 109).

O imperativo moral do supereu se esforça para dirimir completamente sua outra vertente, qual seja, a do imperativo de gozo. No entanto, quanto mais intensa é a tentativa moral de supressão do gozo, necessariamente sexual, mais forte se faz o seu retorno na forma de violência, ou seja, na forma de seu estatuto mais fundamental, o de pulsão de morte. O enrijecimento moral performado pelo discurso do cidadão de bem que tenta elidir as múltiplas expressões da sexualidade humana produz, como uma espécie de efeito rebote, atos de violência que possibilitam o gozo aparecer em sua dimensão mais mortífera.

Assim, uma estratégia se enuncia. Estratégia pulsional, se pensada no âmbito da singularidade subjetiva, e política quando inserida no contexto de um determinado discurso social. Se o cidadão de bem não pode gozar na dimensão da sua sexualidade, ele pode gozar ao violentar o outro pelo que concerne à sexualidade desse último. Gozo que remete a uma erótica singular da pulsão de morte. Um exemplo do desdobramento dessas condições pode ser claramente notado nos atos de homofobia que se acentuam em nossa sociedade atual. Temos aqui em jogo a articulação de duas esferas: a da agressividade (imaginário) e a da violência (simbólico).

Campos (2015, p. 106) afirma que "a violência e o poder são máscaras do supereu que incidem sobre a sociedade". Propomos, a partir disso, pensar o discurso do cidadão de bem como complemento da paramentação com a qual se adorna o supereu na sociedade contemporânea. Discurso que faz ressoar a severidade da censura que, em nome do conjunto de certos ideais como a defesa da moral, da família e dos bons costumes (ideal do Eu), resulta em imposições violentas de cerceamento do outro.

Para o suposto moralmente límpido cidadão de bem, o campo da sexualidade é particularmente perigoso. Retomemos aqui o caráter de duplicidade da lógica do supereu, no qual a lei tem duas configurações. Primeiramente temos a lei em sua vertente simbólica e reguladora, ou seja, a lei da consciência moral. Essa lei, nós a ouvimos bem por meio dos enunciados doutrinais do "cidadão de bem". Ele manifesta repúdio, indignação e nojo pelo que toca particularmente o campo insondável e anormativo do sexual. O desejo que pode 
advir do encontro com esses objetos tão depreciados é um risco que não se pode correr. Por isso é preciso afastá-los de todas as formas possíveis, inclusive criminalizando-os.

Por outro lado, o que fundamenta essa reação no cidadão de bem é o medo que ele vive de confrontar-se com a outra face de seu próprio ser, que almeja o indulto das restrições para comandar uma coisa, e uma coisa apenas: goza! Dito de outro modo, podemos sustentar que o repúdio, a indignação e o nojo são mensagens próprias do cidadão de bem que ele recebe do Outro de forma invertida. Se nos propusermos aqui o desafio de desinvertê-las, temos: "tenho repúdio, indignação e nojo de mim mesmo, por haver em mim algo que, à minha revelia, me comanda a subverter valores que eu tanto prezo, tais como os da moral, da família e dos bons costumes". Eis a dura condição paradoxal do supereu. Quanto mais intenso for a ordem do supereu para transgredir as barreiras dos seus ideais, mais rígido o sujeito se tornará na vida do engajamento de defender a garantia desses mesmos ideais.

O discurso do cidadão de bem, aquele que ressoa como ode à violência, é justamente uma alternativa para que se possa dar vazão ao gozo pulsional obturado pelo imperativo moral. Desse modo, o cumprimento do imperativo de gozo pela violência e poder se exacerba ali mesmo onde parece estar sendo negada a sexualidade. Afinal, é bom lembrar que, nesse aspecto, a pulsão por excelência é sempre pulsão de morte (Freud, 1920[2010b]).

\section{Queermuseu: a mostra do enigma sexual}

Em setembro de 2017, uma exposição de arte foi cancelada no Santander Cultural, em Porto Alegre. A mostra "Queermuseu - Cartografias da Diferença na Arte Brasileira" foi vetada com cerca de um mês de exposição. O motivo que levou ao cancelamento da exibição partiu de pessoas mobilizando-se para protestar nas redes sociais, alegando que a exposição promovia blasfêmia contra símbolos religiosos e apologia à zoofilia e à pedofilia. As queixas foram reforçadas pela participação do Movimento Brasil Livre (MBL), que, além de pedir o encerramento da exposição, incitou um boicote ao Banco Santander. 
É interessante levar em consideração que as críticas dirigidas à mostra de arte em questão orbitaram em torno de um mesmo núcleo, o sexual. Mas como podemos entender esse movimento que, pautado na premissa de defesa da moral, anseia expurgar o sexual do campo artístico? O que ficou à mostra nessa exposição que produziu tal efeito de horror no virtuoso cidadão de bem? Teremos algum apoio nessa discussão retomando o texto de Freud (1908[1996f]), "Moral sexual 'civilizada' e doença nervosa moderna”.

A perspectiva freudiana concebe que a noção de civilização está necessariamente atrelada à supressão das pulsões sexuais. A renúncia de parte de nossos impulsos sexuais é o que nos permite sustentar o convívio com o outro em algum modo de laço social. Assim, a moral sexual é um traço estrutural de qualquer cultura. Não há sociedade que não se fundamente numa lei que estabeleça um ponto de limite para o gozo. Lacan (19691970[2007]) atribui aos laços sociais a função de aparelhamento disso que escapa da apreensão da linguagem, é o que simultaneamente possibilita e interdita o gozo, ou, nos servindo ainda de outro significante, o sexual. Escreve Santos e Ceccarelli (2010, p. 23) que

[...] legislar acerca dos prazeres parece ser uma astúcia inerente ao trabalho de cultura (Kulturarbeit) para manter a coesão dos grupos humanos. O que se depreende de tudo isto é que o discurso sobre a sexualidade é um artefato criado para lidar com o mistério do sexual que nunca será objetivamente observado e controlado. A ordem discursiva criada pela cultura jamais dará conta desse enigma, cujas manifestações são provas irrefutáveis de que não somos senhores em nossa própria casa. Sendo o inconsciente sexual, suas produções são muitas vezes sentidas, tanto pelo sujeito quanto pela cultura, como algo da ordem do estranho (Unheimlich).

No entanto, mesmo reconhecendo que a moral sexual é de fato um efeito que se produz na confecção de uma cultura, Freud (1908[1996f]) apresenta uma perspectiva que devemos levar em consideração. O texto freudiano se propõe a pensar quais seriam, digamos assim, os custos e os benefícios de restringirmos os impulsos sexuais pela via da regulamentação moral no contexto de uma sociedade. A conclusão de Freud é a de que, se por um lado, a moral sexual é um elemento impreterível para a formação cultural (moral sexual natural), por outro, a demasiada intolerância das restrições morais põe em risco a 
própria instituição cultural (moral sexual civilizada). Ou seja, quando a moral deixa de ser apenas um dos elementos reguladores que possibilita o agrupamento humano, e passa a ser uma arma tirânica que só admite nada menos do que o excesso de moralismo, aí o perigo se volta contra os próprios propósitos da civilização. Nesse sentido, o gozo desmedido reaparece com toda sua potência aniquiladora.

Voltemos então para a discussão da exposição "Queermuseu". As expressões artísticas são reconhecidamente tomadas por Freud como um clássico exemplo de sublimação, que é a "capacidade de trocar seu objetivo sexual original por outro, não mais sexual, mas psiquicamente relacionado com o primeiro" (Freud (1908[1996f]) p. 174). O que parece estar no cerne temático da exibição em questão é promover um "curto-circuito" nessa relação entre arte como sublimação de conteúdos sexuais, para mostrar aquilo que, por mais perturbador que possa ser para alguns, é um componente indissociável da sexualidade humana, sua característica "perversa polimorfa".

Em seus "Três ensaios sobre a teoria da sexualidade", Freud (1905[1996e]) sustenta que a gênese da sexualidade humana, ou seja, sua manifestação ainda na infância, é marcada por uma orientação perversa de maneiras variadas. Seu estatuto perverso reside no fato de a sexualidade humana não estar a serviço de funções ligadas à conservação (reprodução) da vida - ainda que possa se apoiar nelas -, mas sim submetida à busca da satisfação. A noção de "apoio" é importante nesse contexto, pois visa evidenciar a diferença no humano entre a manifestação instintual e a pulsional. Enquanto a necessidade se endereça para a satisfação instintual, o desejo se articula à satisfação pulsional. Segundo Garcia-Roza (2011, p. 96): "o que vai ser colocado nos Três ensaios é a perda da inocência infantil".

Muitas das queixas dirigidas à mostra "Queermuseu" se direcionaram a algumas obras em específico, como o caso da série de pinturas intitulada "Criança Viada", de Bia Leite. As telas traziam desenhos de meninos com frases como "criança viada travesti da lambada" e "criança viada rainha das águas". Os cidadãos de bem ficaram furiosos, afirmando que dizer que uma criança é "viada" implica em sexualizar sua imagem, o que classificaria um caso de apologia à pedofilia. Aos olhos do genérico cidadão de bem, as 
telas exibiam um crime, mas contra o quê? Vejamos uma das posições de Freud (1913[1996g], p. 186) sobre a arte:

A arte é uma realidade convencionalmente aceita, na qual, graças à ilusão artística, os símbolos e os substitutos são capazes de provocar emoções reais. Assim, a arte constitui um meio-caminho entre uma realidade que frustra os desejos e o mundo de desejos realizados da imaginação - uma região em que, por assim dizer, os esforços de onipotência do homem primitivo ainda se acham em pleno vigor.

Nessa citação, Freud aponta para uma correlação entre a expressão artística e a expressão de desejos. É a premissa psicanalítica da sublimação: o artista expurga seus desejos inconscientes ao veiculá-lo em uma produção artística cuja matéria-prima, pensando a partir da subjetividade do artista, é sempre o sexual. Poderíamos conjecturar que a exposição "Queermuseu", ao tratar do sexual sem os recobrimentos e disfarces que usualmente a ação sublimatória produz, desnuda a composição perversa polimorfa que marca a organização mais primitiva, e por isso mais elementar da sexualidade humana. Nesse sentido, o horror reverberado em alguns espectadores das obras diante do estranho que se exibia nas telas, talvez, nos indique a dificuldade dessas pessoas em lidar com a própria dimensão desejante e com aquilo que predispõe qualquer condição para o desejo: a castração.

A arte tem mesmo uma tendência ao desassossego. Não é por acaso que, por exemplo, quando uma criança é pega em flagrante descontruindo, sujando, bagunçando, ou até mesmo quebrando algo, frequentemente ouvimos alguém dizer que ela estava "fazendo arte". Lembremos que, para Freud (1913[1996a], p. 85), "poder-se-ia sustentar que um caso de histeria é a caricatura de uma obra de arte". E que, portanto, há alguma homologia entre o que se produz no efeito de uma obra artística e o que se apresenta no funcionamento lógico de um caso de histeria. Convém retomarmos então alguns pontos acerca do discurso histérico para vermos se podemos extrair disso algo que nos ajude a pensar agora a articulação que Freud propõe entre arte e desejo. 
Dentre as quatro formações discursivas que Lacan (1969-1970[2007]) demonstra no seminário XVII, o discurso da histérica é aquele que coloca o desejo em evidência. O sujeito dividido (\$), na posição de agente discursivo, denota que é a condição de falta, e por isso desejante, que põe em marcha o funcionamento desse discurso. Podemos formular que, na linha superior do discurso histérico, se inscreve a impossibilidade de sanar o desejo $(\$->$ S1), enquanto que a linha inferior diz da impotência do saber diante do real que a palavra não recobre $(\mathrm{a}<-\mathrm{S} 2)$. Esse discurso então enuncia o fracasso do mestre pela impotência do saber, o que resulta na manutenção da falta em posição de verdade, criando a condição para que o desejo se sustente e prevaleça no circuito discursivo.

Se tomarmos então as manifestações artísticas da exibição "Queermuseu" como protótipos cuja caricatura teria semelhanças com o discurso histérico, tornam-se mais compreensíveis as acusações dirigidas aos artistas e curadores da mostra. O horror do cidadão de bem não está referido à condição que ele abomina no outro, mas àquilo que, ao ser mostrado no campo do Outro, o faz se deparar com o que repudia em si mesmo. A exibição de Porto Alegre desvela a desnaturalização da sexualidade humana para dar prevalência à sua condição pulsional, cujos objetos são os mais variados possíveis (perversa polimorfa). Isso faz ruir qualquer possibilidade de apreensão padronizada de um saber sobre a sexualidade humana, assim como no discurso histérico a arte presente no "Queermuseu" denuncia a impotência do saber sobre o mistério do sexual.

Em seus "Três ensaios sobre a teoria da sexualidade", Freud (1905[1996e], p. 183) disserta sobre uma "pulsão de saber" que, na criança, "é atraída, de maneira insuspeitadamente precoce e inesperadamente intensa, pelos problemas sexuais, e talvez seja até despertada por eles". Desde tenra infância, os falantes são confrontados pelos "problemas sexuais", é instigante considerar que a sexualidade para o resto dos animais, não perpassados pela linguagem, não constitui uma problemática, o saber instintual articulado à necessidade de conservação e reprodução da vida elege objetos fixos cuja relação se estabelece de maneira inequívoca. Não funciona assim com os humanos, a imersão no universo simbólico faz com que esse saber instintual perca espaço para um não-saber que se instaura como efeito de nossa inscrição pulsional, os objetos não são 
mais determinados pela necessidade, mas pelo desejo; ou seja, a questão sexual humana é irrevogavelmente problemática.

A pulsão de saber, pontua Freud (1905[1996e], p. 183), se relaciona a "uma forma sublimada de dominação". Diante da inefável questão da sexualidade, uma das estratégias para abordar seus enigmas é a tentativa de dominação pelo saber. Existem muitas maneiras pelas quais a civilização tenta dominar a sexualidade humana. As religiões, as leis, as ciências e as normas morais são exemplos de estratégias de dominação do sexual. E vimos, com Freud (1908[1996f]), que, apesar de ser um elemento constituinte para qualquer formação cultural, o excessivo recrudescimento no domínio da sexualidade é um infortúnio para a própria organização social.

Pois bem, o que apreendemos dessa manifestação contra a exibição "Queermuseu" parece se relacionar justamente com a tentativa de dominar, pela censura (ou boicote), o insondável que caracteriza a constituição pulsional da sexualidade humana. Tal como um protesto histérico, a arte exibida no "Queermuseu" põe à mostra a impotência de um saber moral frente ao desejo humano que insiste em escapar de toda e qualquer tentativa de normatização. O crime e a blasfêmia vistos pelo cidadão de bem ofendem seu ideal totalizante que almeja recobrir as fissuras do sexual com a argamassa do saber. Eis o que se constitui como legisladamente sagrado para esses sujeitos-cidadãos: a integralidade do Outro.

O cidadão de bem (estamos nos referindo predominantemente a um discurso e não a um sujeito específico) é aquele que se pretende "íntegro", e tal significante merece desdobramento. Podemos destacar algumas características de alguém dito íntegro, tais como: conduta irrepreensível, totalmente probo, honesto, incorruptível etc. Percebam que tais adjetivos representam muito bem - pelo menos no campo do enunciado - as bandeiras erguidas por aqueles que se colocam como defensores da família, da moral e dos bons costumes. A integridade, nesse aspecto, corresponde a uma suposta retidão do caráter e tem suas aspirações pautadas em ideias altamente cerceadores.

Entretanto, temos também implicada no significante "íntegro" uma outra vertente semântica de nosso particular interesse, a saber, sua utilização para se referir a algo “inteiro", "completo" e, portanto, não dividido. Essa fantasia de integridade tenta recobrir a 
condição dividida inerente a todos os falantes, afinal de contas, se tem algo que podemos afirmar que se instaura a partir do advento do discurso psicanalítico é justamente a assunção da clivagem subjetiva, dito de outro modo, a descoberta-invenção do inconsciente é o que vem para sustentar que "o Eu não é senhor em sua própria casa" (Freud, 1917[2010c], pp. 250-251). Essa noção de integridade, então, corresponde ao "mito do Eu ideal, do Eu que domina, do Eu pelo qual alguma coisa é pelo menos idêntica a si mesma" (Lacan, 1969-1970[2007], p. 65), ou seja, o mito do Eu assenhorado de sua própria casa, unívoco, consistente, enfim: íntegro.

Assim, o que a Psicanálise ratifica é a impossibilidade dessa integridade subjetiva. Por mais que se esforce para tal, o cidadão de bem, figura mítica da integridade, sempre será "corruptível", "improbo" e "desonesto" em sua dimensão desejante. No inconsciente, não há lugar para valores morais, edificações virtuosas e tampouco restrições normativas. As representações pulsionais pertencentes ao sistema inconsciente têm apenas um objetivo: a satisfação. E, como vimos anteriormente, a sexualidade humana, por sua vertente pulsional, busca satisfação nos objetos mais variáveis possíveis, por isso Freud se serve da expressão "perversa polimorfa".

No que diz respeito à análise que nos propomos a fazer sobre a indignação suscitada em alguns pela mostra "Queermuseu", o que parece ter horrorizado esse cidadão de bem - referência discursiva que veicula o mito do herói guerreando para defender a família, a moral e os bons costumes - foi o encontro com aquilo que mostra, exibe e expõe sua própria constituição subjetiva inapelavelmente perpassada pelo campo do sexual, marca pulsional que, nos falantes, é avessa a qualquer pretensão de integralidade. A clivagem subjetiva que inaugura o impossível de tudo saber sobre o sexo faz sucumbir os ideais de normatização que tentam impor domínios morais sobre o desejo. Dizendo ainda de uma outra maneira, o desejo, índice por excelência do humano, é ilesgislável por qualquer regimento normativo.

Diante disso, propomos interpretar que a resistência manifesta pelo cidadão de bem diante da exibição "Queermuseu" não diz da qualidade ou do valor artístico das obras lá expostas, mas aponta, no entanto, para o que há de mais diversamente perverso na 
constituição sexual também (e principalmente) daquele que se ambiciona assepticamente íntegro. Nessa perspectiva, censurar ou boicotar a exibição é uma forma de tentar censurar e boicotar as próprias tendências pulsionais que divergem desse ideal de Eu miticamente revestido na figura discursiva do cidadão de bem. O investimento superegoico que se expressou por meio do ataque dirigido aos artistas e curadores das obras mostra o enrijecimento subjetivo que esse cidadão de bem parece precisar sustentar para que não escape nada que possa revelar seu desejo. Sobre esse aspecto, fazemos coro com Calligaris (2017): "Os incendiários, às vezes, se fazem de bombeiros".

\section{Considerações finais}

Frente a essas considerações acerca do supereu cultural na contemporaneidade que parece apresentar-se, em uma de suas modalidades, pelo discurso do cidadão de bem, como podemos pensar a posição ética da Psicanálise em seus desdobramentos políticos? Se o supereu (tanto o "individual" quanto o cultural) é, por um lado, uma moral guiada por ideais de conduta e, por outro, constituído por um inflexível ordenamento de gozo, a Psicanálise é justamente o que se coloca como barreira tanto aos ideais de uma moral exacerbada quanto aos intentos de um gozo desmedido.

Diante do apelo moral que almeja tornar-se modelo de uma conduta normatizante, a posição psicanalítica propõe uma perspectiva ética que responsabiliza cada sujeito a se haver com aquilo que the é mais singular. Sem modelos e sem manuais, o discurso psicanalítico incita à invenção para cada sujeito lidar com seu sintoma. Quanto à dureza do ordenamento de gozo, o dispositivo analítico é o que possibilita ao sujeito reformular sua relação com o gozo, erigindo barreiras que o permite permeabilizar esse comando do supereu. A análise encaminha os sujeitos para um mais além do supereu (Campos, 2015).

Mas como lidar com o que não se trata? Já que para o supereu não tem remédio (Campos, 2015), é preciso ao menos circunscrever o posicionamento ético que concerne a todos aqueles que pretendem fazer ressoar o discurso psicanalítico. Para além da função analítica que se exerce nos consultórios, faz-se contundente pensar sobre a importância do discurso psicanalítico em suas articulações sociais. Afinal, um psicanalista precisa sempre 
estar atento à subjetividade de sua época e aos desafios que se instauram no campo do social. Da mesma maneira que o inconsciente tem seus desdobramentos no campo da política e das construções sociais, aquilo que se evidencia na experiência clínica nos convoca a pensar a respeito dos paradigmas sociais que se constituem, por exemplo, na voz do supereu cultural que se sonoriza pela garganta do cidadão de bem.

No fim do texto "Moral sexual 'civilizada' e doença nervosa moderna", Freud (1908[1996f]) sustenta que, embora não seja atributo do psicanalista propor reformas sociais, caberia a ele, como tal, defender a necessidade de tais reformas. Essa afirmação freudiana nos parece conter uma enorme importância para aquilo que concerne à posição ética do psicanalista diante dos impasses sociais inerentes à subjetividade de sua época.

Freud ressalta que não é atributo do psicanalista propor reformas socais. No entanto, ele faz questão de defender um posicionamento, essencialmente político, diante dos desafios que se instauram no campo da cultura. Assim, acreditamos que, com a confecção deste artigo, estamos contribuindo para convocar o discurso psicanalítico a operar em seu estatuto ético na problematização do supereu cultural na contemporaneidade na modalidade em que ele se apresenta adornado pelas reivindicações morais do cidadão de bem.

A voz é a expressão elementar do supereu e, em nossa sociedade atual, nos parece que ela é majoritariamente vocalizada pelo cidadão de bem. Neste trabalho, tentamos criar condições para que essa voz seja ouvida, não apenas na dimensão do seu enunciado, mas principalmente no âmbito de sua posição enunciativa; debruçamo-nos sobre o que diz de si esse cidadão de bem quando se presta a dizer do outro; postulamos que ele diz do supereu que vigora na subjetividade de nossa época. Marcar as intercorrências que se articulam na posição enunciativa de um determinado discurso já é um ato que está eticamente fundamentado na lógica psicanalítica.

Em um momento sociopolítico (supereu cultural) como o que estamos vivenciando atualmente no Brasil, é possível evocar o jogo de significantes mencionado por Campos (2015), qual seja, diante do clamor por um père sévère (pai severo), só nos resta persévérer (perseverar) no intento ético da Psicanálise que defende a alteridade e a coexistência da 
diferença. Nesse ponto, Freud (1930 [1996b], p. 148) se faz ouvir: "Mas quem pode prever com que sucesso e com que resultado?"

\section{Referências}

Bauman, Z. (2001). Modernidade líquida (P. Dentzien, Trad.). Rio de Janeiro: Zahar.

Calligaris, C. (2017). Brasileiros, mais um esforço para sermos liberais. Folha de S.Paulo, Recuperado de https://www1.folha.uol.com.br/paywall/login.shtml?https://www1.folha.uol.com.br/ colunas /contardocalligaris/2017/09/1920356-brasileiros-mais-um-esforco-parasermos-liberais.shtml.

Campos, S. (2015). Supereu/Uerepus: das origens aos seus destinos. Belo Horizonte: Escola Brasileira de Psicanálise.

Freitas, J. (2014). A alegoria moderna de Walter Benjamin: Passagens, Baudelaire e mercadoria. Revista Investigações, 27(1), 1-25.

Freud, S. (1996a). Totem e Tabu. In S. Freud. Edição standard brasileira das obras completas de Sigmund Freud (Vol. XIII, pp. 21-162). Rio de Janeiro: Imago. (Trabalho original publicado em 1913).

Freud, S. (1996b). O mal-estar na civilização. In S. Freud. Edição standard brasileira das obras completas de Sigmund Freud (Vol. XXI, pp. 73-148). Rio de Janeiro: Imago. (Trabalho publicado originalmente em 1930).

Freud, S. (1996c). Sobre o narcisismo: uma introdução. In S. Freud. Edição standard brasileira das obras completas de Sigmund Freud (Vol. XIV, pp. 81-108). Rio de Janeiro: Imago. (Trabalho originalemnte publicado em 1914). 
Freud, S. (1996d). O ego e o id. In S. Freud. Edição standard brasileira das obras completas de Sigmund Freud (Vol. XIX, pp. 25-80). Rio de janeiro: Imago. (Trabalho originalmente publicado em 1923).

Freud, S. (1996e). Três ensaios sobre a teoria da sexualidade. In S. Freud. Edição standard brasileira das obras completas de Sigmund Freud (Vol. VII, pp. 119-209). Rio de Janeiro: Imago. (Trabalho original publicado em 1905).

Freud, S. (1996f). Moral sexual "civilizada" e doença nervosa moderna. In S. Freud, Edição standard brasileira das obras completas de Sigmund Freud (Vol. IX, pp. 169-186). Rio de Janeiro: Imago. (Trabalho publicado originalmente em 1908).

Freud, S. (1996g). O interesse científico da Psicanálise. In S. Freud. Edição standard brasileira das obras completas de Sigmund Freud (Vol. XIII, pp. 169-192). Rio de Janeiro: Imago. (Trabalho originalmente publicado em 1913).

Freud, S. (2010a). O mal-estar na civilização. In S. Freud. Obras completas (Vol. 18, 1a ed., pp. 13-122, P. C. de Souza, Trad.). São Paulo: Companhia das Letras. (Trabalho original publicado em 1930).

Freud, S. (2010b). Além do princípio do prazer. In S. Freud. Obras completas (Vol. 14, 1a ed., pp. 161-239, P. C. de Souza, Trad.). São Paulo: Companhia das Letras. (Trabalho original publicado em 1920).

Freud, S. (2010c). Uma dificuldade da Psicanálise. In S. Freud. Obras completas (Vol. 14, 1 a ed., pp. 241-251, P. C. de Souza, Trad.). São Paulo: Companhia das Letras. (Trabalho original publicado em 1917).

Freud, S. (2011). Psicologia das massas e análise do Eu. In S. Freud. Obras completas (Vol. 15, pp. 13-113, P. C. de Souza, Trad.). São Paulo: Companhia das Letras. (Trabalho original publicado em 1921).

Garcia-Roza, L. A. (2011). Freud e o inconsciente (2a ed., 23a reimp.). Rio de Janeiro: Zahar. 
Lacan, J. (1998a). A ciência e a verdade (V. Ribeiro, Trad.). In J. Lacan (Org.). Escritos (pp. 869-892). Rio de janeiro: Zahar. (Trabalho original publicado em 1966).

Lacan, J. (1998b). Posição do inconsciente, no Congresso de Bonneval. (V. Ribeiro, Trad.). In J. Lacan (Org.). Escritos (pp. 843-864). Rio de Janeiro: Zahar. (Trabalho original publicado em 1960, retomado em 1964).

Lacan, J. (2007). O seminário, livro XVII: O avesso da Psicanálise (A. Roitman, Trad.). Rio de Janeiro: Zahar. (Trabalho original publicado em 1969-1970).

Lacan, J. (2008). O seminário, livro VII: A ética da Psicanálise (A. Quinet, Trad.). Rio de Janeiro: Zahar. (Trabalho original publicado em 1959-1960).

Lustoza, R. Z., Cardoso, M. J. E., \& Calazans, R. (2014). “Novos sintomas” e declínio da função paterna: um exame crítico da questão. Ágora, Rio de Janeiro, $17(2), 201-213$. doi: $10.1590 /$ S1 516-14982014000200003.

Nasio, J. D. (1997). Lições sobre os 7 conceitos cruciais da Psicanálise (V. Ribeiro, Trad.). Rio de Janeiro: Zahar.

Santos, A. B. R, \& Ceccarelli, P. R. (2010). Perversão sexual, ética e clínica psicanalítica. Revista latinoamericana de psicopatologia fundamental, 12(2), 316-228. doi: $10.1590 /$ S1 $415-47142009000200006$.

Vanier, A. (2002). O sintoma social. Ágora, Rio de Janeiro, 5(2), 215-217. doi: $10.1590 /$ S1 $516-14982002000200001$.

Recebido em: 19/5/2018

Aprovado em: 6/11/2018 